\title{
XXI. Über Quarzzwillinge nach R (Estérel-Typus).
}

\author{
Von \\ Julien Drugman in Oxford.
}

Kürzlich beschrieb ich ${ }^{1}$ ) eine neue Art Quarzzwillinge nach $R\{10 T 1\}$, die sich durch große Regelmäßigkeit der Ausbildung auszeichnete. Sie kommt unter den losen Bipyramiden aus dem zersetzten Esterellit vor. Wegen der eigenartigen und modellartigen $\Lambda$ usbildung dieses aus zwei gleich großen Bipyramiden bestehenden Zwillings schlug mir V. Goldschmidt vor, diese neue Varietät seines $\triangleright$ Griesernthaler Gesetzes « als »Estérel «-Typus zu bezeichnen. Darüber erschien dann eine kurze Notiz in dieser Zeitschrift ${ }^{2}$, worin auch über das Auffinden von anderen Exemplaren dieses Estérel-Typus, sowie von ähnlich gebauten $\xi$-Zwillingen aus derselben Gegend berichtet wurde.

Bis jetzt waren solche $Z$ willinge nur im Estérel gefunden worden, dort aber in ziemlich großer Anzahl. Ich habe schon gegen drei Dutzend $R$-Zwillinge und fünf bis sechs $\xi$-Zwillinge dort gefunden; darunter viele recht scharfe.

Wegen der sehr großen Ähnlichkeit in der Ausbildung der Porphyrquarze von verschiedenen Gegenden - die gleichmäßige Entwickelung der sechs »Pyramidenflächen* und das Fehlen des Prismas - lag die Vermutung nahe, daB diese unter ähnlichen Bedingungen auskrystallisierten Quarze auch dieselben Zwillingsgesetze zeigen würden. Bei meiner Rückreise aus dem Estérel besuchte ich daher die Mineralienhandlungen von Grebel und Wendler in Genf und von Dr. Krantz in Bonn, um unter ihren Quarzvorräten nach Zwillingen zu suchen und fand in der Tat solche.

Bei Grebel und Wendler waren es nur ganz kleine Bipyramiden aus Ungarn, die sehr regelmäßig ausgebildet waren. Eine war aber weniger einfach und wurde als $Z$ willing nach $\xi$ erkannt.

1) Mineralogical Magazine 1911, 16, 112-117.

2) Dlese Zeitschr. 1912, 50, 598-599. 
Bei Krantz waren Porphyrquarze aus Verespatak, Ungarn, und solche aus dem Uralgebirge, letztere ohne nähere Fundortsangabe, vorrätig. Eine von den Bipyramiden aus Verespatak war ein typischer $R$-Zwilling vom Estérel-Typus, nur daß einer von den zwei Individuen kJeiner als der andere war. Besonders deutlich war der einspringende Winkel oben, die übrigen Teile waren durch parallele Verwachsungen und Löcherung weniger gut zu erkennen.

Unter den Uraler Krystallen, die meist ganz einfach und ziemlich scharf waren, war einer, der weniger einfach aussab. Es saßen darauf mehrere kleinere abgeplattete Kryställchen, die meisten in paralleler Stellung, drei aber anders gerichtet waren. Von diesen war einer anscheinend unregelmäßig aufgewachsen, die anderen zwei lagen aber symmetrisch auf dem großen. Einer lag mit paralleler $R$-Fläche auf einer $R$-Fläche des großen Krystalles; zugleich war die Zone zwischen oberer und unterer Pyramidenfläche für beide Krystalle parallel, ihre Spitzen lagen aber umgekehrt. Dieser war also ein Zwilling nach $R$, von gleicher Ausbildung wie Goldschmidt's Griesernthaler Stück. Das andere Kryställchen lag parallelkantig auf einer Kante zwischen zwei benachbarten Pyramidenflächen des großen und zugleich waren diese Flächen für beide Krystalle parallel. Hier aber waren die Spitzen auch entgegengesetzt gerichtet. Dieser war nach $\xi$ verzwillingt. Auf dem einen Krystall saßen also beide Arten von $Z$ willingen!

In London endlich fand ich bei Gregory Porphyrquarze, die aus Cornwall stammten. Diese waren weniger scharf und von Feldspat etwas bedeckt, vier davon konnte ich aber als $\mathrm{Zwillinge} \mathrm{nach} R$ erkennen. Diese 'waren wie der Uraler Krystall ausgebildet, indem ein kleineres Individuum parallelflächig auf dem großen mit entgegengerichteter Spitze saß. Ein Krystall, der jetzt im British Museum liegt, hatte sogar auf zwei Seiten Zwillinge nach $R$. Andere Bipyramiden, welche Prof. Bowman aus Cornwall mitgebracht hatte, zeigten typische symmetrische $R$-Zwillinge und $\xi$-Zwillinge.

Das Vorkommen von $R$-Zwillingen unter Porphyrquarzen aus vier verschiedenen Gegenden beweist, daß dieses Gesetz nicht nur eine interessante lokale Erscheinung ist, sondern ein für diesen Quarztypus ganz allgemeines Gesetz. Wegen der sehr regelmäßigen Ausbildung und Häufigkeit, besonders im Estérel, verdient es wohl, als besonderer Typus, der :Estérel-Typus a genannt zu werden. $\xi$-Zwillinge kommen auch unter diesen Bipyramiden vor, dem Anschein nach aber viel seltener. Es würde interessant sein, diese Annahme durch Aufsuchen von Zwillingen unter Bipyramiden aus einer noch größeren Zahl von Fundorten zu controllieren. 